\title{
ELITE ECONÔMICA NO BRASIL: DISCUSSÕES ACERCADA INTERNACIONALIZAÇÃO DA CARREIRA DE EXECUTIVOS BRASILEIROS.
}

\author{
Markus Pohlmann
}

\author{
Elizângela Valarini
}

\begin{abstract}
RESUMO
O objetivo principal do artigo é examinar a hipótese da internacionalização da alta gerência industrial brasileira por meio do grau de internacionalização de sua carreira no contexto da globalização. Tal hipótese está intrinsicamente articulada às teorias da globalização que sugerem o surgimento de uma elite econômica global cuja particularidade seria, entre outros aspectos, seu alto desempenho e sua alta mobilidade social. Por meio da observação da biografia e da trajetória profissional, assim como da mobilidade internacional de altos executivos no Brasil, pretende-se verificar a ocorrência um novo padrão de carreira, ou seja, o surgimento de carreiras globais como efeito do processo de globalização.
\end{abstract}

PALAVRAS-CHAVE: elite econômica brasileira; executivos brasileiros; top manager; carreira internacional; recrutamento internacional.

\section{INTRODUÇÃO ${ }^{1}$}

A emergência de uma elite econômica global ${ }^{2}$, composta por top managers $^{3}$ e profissionais altamente capacitados, é um dos principais pressupostos das teorias mainstream da globalização (BECK, 1997; SKLAIR; 2001) ${ }^{4}$. Tal grupo se distinguiria além de outros aspectos, por sua alta mobilidade internacional e alto desempenho profissional (BECK, 1997; SKLAIR, 2001). Segundo Beck (1997) as fronteiras politicogeográficas não desempenhariam papel algum para esse grupo, uma vez que ele poderia escolher onde viver, trabalhar e até mesmo onde pagar seus impostos. Ancorada nessa idéia Moss-Kanter (1999) enfatiza o aparecimento de mercados globais para profissionais altamente capacitados, dentre eles executivos de alto escalão. Devido a sua alta qualificação e desempenho

1 Agradecemos aos pareceristas da Revista de Sociologia e Política pelas sugestões a este artigo.

2 O termo "elite econômica" descreve exclusivamente o grupo formado por atores que ocupam altas posições gerenciais na economia. Sendo assim, está sendo chamado aqui de "elite econômica" o grupo formado por presidentes, diretores gerais, diretores executivos, chief executive officers (CEOs) etc. das maiores indústrias no Brasil, sejam elas brasileiras, sejam multinacionais. $\mathrm{O}$ termo elite não está aqui articulado a nenhum discurso de classe, origens sociais, características pessoais, qualificações e/ou competências (POHLMANN, 2011b).

3 Entre top managers estão incluídos todos os diretores executivos, CEOs, diretores gerais e presidentes industriais.

4 Para críticas sobre o tema, cf. Pohlmann (2006; 2009a). profissional, tais profissionais como CEOs, diretores gerais e presidentes de grandes corporações seriam disputados internacionalmente por organizações transnacionais. Tal fenômeno é tratado pela autora de war of talents, o qual indicaria o aparecimento de uma concorrência internacional por profissionais altamente capacitados, por empresas transnacionais, dando assim condições para o surgimento de modelos de carreiras transnacionais (idem).

Esse processo de internacionalização da carreira levaria ao surgimento de novos padroes e sistemas de carreiras, os quais deixariam de ser orientados por organizacoes e marcados por valores locais. Estudos sociológicos questionam teorias a respeito do desenvolvimento de carreiras, nas quais o individuo é colocado como o único responsável pela sua própria ascensão profissional (ARTHUR, HALL\& LAWRENCE, 1989; GUNZ, EVANS \& JALLAND, 2000). Diante de uma perspectiva sociológica, carreiras são compreendidas tanto como ascenção quanto descenção de posições dentro de uma organização. Elas são contruídas dentro de organizações e orientadas a elas. Socialmente, carreiras são carregadas de atributos como sucesso e insucesso profissional. Isso significa que as organizações desempenham um papel muito importante, na condução e orientação da carreira (LUHMANN, 2000; POHLMANN, 2006; 2009a; POHLMANN \& BÄR, 2009). Além disso, valores, principios e crenças sociais, assim como aspectos culturais exercem uma certa influencia nos padrões e sistemas de carreira em diferentes culturas (POHLMANN, 2006; 2009a; POHLMANN \& BÄR, 2009). 
O objetivo principal deste artigo é discutir os primeiros resultados de uma pesquisa empírica ainda em andamento a respeito da internacionalização do top management nas maiores indústrias do Brasil. A questão abordada trata-se apenas de uma das hipóteses investigadas na pesquisa em andamento, intitulada " $\mathrm{O}$ novo espirito do capitalismo no top management"5, cujo objetivo é verificar, por um lado, o surgimento de uma elite econômica global, investigada por meio da internacionalização da carreira de altos executivos, sua socialização dentro das organizações e seu mecanismo de recrutamento. Por outro lado, esta pesquisa tem como objetivo verificar o mecanismo de reprodução de valores capitalistas, baseados nas teorias de Max Weber, em várias regiões do mundo, por meio dos estudos da orientação da ação de top managers, no intuito de verificar um processo de convergência de valores e condutas neoliberais, os quais seriam dissiminados por meio de novos conceitos de gerenciamento empresarial (BOLTANSKI \& CHAPELLO, 2009; POHLMANN, 2011b). Este trabalho tem como objetivo principal investigar empiricamente uma possível mudança no padrão de carreira e recrutamento de altos executivos, em decorrência da globalização, à luz de teorias sociológicas. A constatação da existência de carreiras transnacionais, ou ainda chamadas de boderless career (carreiras sem fronteiras), indicaria uma nova forma de recrutamento da elite econômica, ou seja, o mecanismo de recrutamento internacional.

Segundo Ianni (1994), a sociedade global é o novo objeto de estudo das Ciências Sociais. Com isso, novos desafios metodológicos vão sendo colocados para os estudos a respeito da sociedade global. As noções de tempo e espaço, fundamentais para as Ciências Sociais, estão sendo revolucionadas por meio do desenvolvimento tecnológico e científico, que é incorporado e dinamizado pela sociedade global (idem).

\footnotetext{
5 "O novo espírito do capitalismo no top management" tratase de uma série de pesquisas a respeito das mudanças no conjunto de modelos e padrões de interpretação social e formas de justificação do capitalismo, com base nos princípios da conduta de vida, organizacionais e econômicas, através da análise da trajetória profissional de altos executivos industriais e da difisão de conceitos administrativos na mídia especifica para esse grupo-alvo. Tais estudos têm sido desenvolvidos a partir de meados do ano de 2011 em diferentes países, como Alemanha, Suiça, Áustria, Inglaterra, EUA, Coréia do Sul, Japão, China, India, Hong-Kong, Brasil e Argentina. A pesquisa tem coordenação geral do Prof. Dr. Markus Pohlmann, do Instituto de Sociologia Max Weber da Universidade de Heidelberg, e em cooperação, no Brasil, com o Prof. Dr. Paulo Roberto Neves Costa, do Núcleo de Pesquisa em Sociologia Política Brasileira da Universidade Federal do Paraná (NUSP-UFPR).
}

Temas abordados na literatura mainstream da globalização, como o processo de desnacionalização e sua influência na redefinição de novos espaços e valores sociais, passam agora a ser entendidos em uma escala global, e não mais limitados à compreensão da sociedade local; ou, ainda, como a questão do surgimento de uma classe capitalista global, investigada indiretamente neste trabalho (IANNI, 1994; BECK, 1997; SKLAIR, 2001; LÓPEZ-RUIZ, 2004), instigam a investigação empiricas de tais pressupostos. Portanto, pretende-se através da investigação da internacionalização do top management analisar empiricamente a questão do recrutamento internacional da elite econômica, o qual se refere a um dos pressupostos que indicaria a emergência de uma elite econômica global.

A metodologia empregada para o levantamento e análise dos dados discutidos neste trabalho baseia-se em estudos anteriormente realizados na Alemanha e Ásia do Leste, em especial na Coréia do Sul (POHLMANN, 2011b). Sendo assim, pretende-se, aqui, não apenas verificar a hipótese de internacionalização do top management no Brasil, mas, em um segundo momento, comparar os resultados obtidos com pesquisas realizadas em outros países.

Uma pesquisa recentemente realizada (POHLMANN, 2009b) a respeito da internacionalização da alta gerência, e com isso, da carreira de top-managers na Alemanha, na Coréia do Sul e ainda nos EUA, demonstra por um lado, um aumento significativo da mobilidade internacional de presidentes e CEOs de corporações com atuação internacional. No entanto pode-se dizer que a globalização conduz a mudanças nos padrões e sistemas de carreira? Os resultados de tais pesquisas demonstram ainda que a internacionalização do top management, mesmo em corporações multinacionais, encontra-se muito aquém da internacionalização do seu processo produtivo. Assim, a tão discutida mobilidade internacional de tais profissionais parece restringir-se a trocas de postos em diferentes filiais e unidades dentro da própria corporação, fenômeno chamado por Pohlmann e Bär (2009) de internacionalização leve, nas palavras dos autores, light internationalization (idem; POHLMANN, 2006; 2009a).

A compreensão da influência da globalização no padrão de carreira de altos executivos permite-nos compreender não somente a formação e o recrutamento de tal grupo no Brasil, mas ainda revisar alguns pressupostos a respeito desse tema, presentes na literatura sociológica, a fim de verificar a existência de tendências ou mudanças na trajetória de tal grupo. Isso levaria também a investigação de tendências e mudanças no padrão de carreira da elite econômica brasileira. Sendo assim, as discussões levantadas neste artigo não têm a pretensão de descartar ou provar hipóteses a respeito da temática, mas sim de provocar 
discussões sobre esse tema, frequentemente tratadas na literatural internacional.

Discussões envolvendo a metodologia pertinente à pesquisa serão abordadas na segunda seção, contemplando a escolha e a formação da amostragem e o método empregado para o levantamento e análise dos dados da biografia e trajetória profissional dos executivos brasileiros. Na terceira seção serão apresentados e discutidos importantes aspectos a respeito da mobilidade internacional de executivos, baseados em dados estatísticos. Tais discussões estão relacionadas à tese do surgimento de uma boderless career $^{6}$.

Na quarta seção discutiremos os dados levantados no Brasil e o possível modelo de carreira dominante entre os executivos brasileiros e alemães. Em seguida, na quarta seção trataremos brevemente do mecanismo de recrutamento da elite econômica brasileira, por meio do levantamento de algumas hipóteses com relação ao mesmo, baseadas nos dados empíricos recentemente levantados no Brasil.

\section{ASPECTOS METODOLÓGICOS}

Como mencionado acima, a metodologia empregada baseia-se em estudos anteriormente realizados na Alemanha e no Leste Asiático para investigar a elite econômica nesses países (POHLMANN, 2011). Os métodos empregados para o levantamento e análise dos dados correspondem a instrumentos de pesquisa explorativa padronizados, os quais permitem o levantamento de grande quantidade de informações a respeito da amostragem estudada. (FRIEDRICHS, 1990; ATTESLANDER, 2003; DIEKMANN, 2005). Mais especificamente, utilizamos o método de prosopografia (life course analysis) para formação do sampling, padronizando a forma de levantamento e de análise dos dados. Através dessa padronização das informações quantitativas foi possível identificar o grupo a ser estudado e, também, fazer o levantamento de variáveis independentes e dependentes a respeito da origem social, qualificação e trajetória profissional dos diretores gerais, presidentes e CEOs das maiores indústrias no Brasil e ainda das empresas por eles gerenciadas.

Para verificarmos a hipótese a respeito da internacionalização do top management no Brasil, utilizamos uma amostragem contendo representantes, ou seja, presidentes, CEOs e diretores executivos das 100 maiores indústrias no Brasil, a partir do critério das vendas. O sampling foi composto inicialmente por 61 variáveis e o levantamento de dados foi inicialmente realizado por meio da busca de informações online a respeito das três dimensões acima descritas (origem social, qualificação e trajetória profissional).

A formação do sampling foi composta em duas etapas. Em um primeiro momento foram identificadas as 100 maiores indústrias do Brasil, as quais comporiam a amostragem, por meio de rankings e estudos já existentes. O critério utilizado para a seleção das empresas foi o faturamento da organização no ano de 2010. Para a identificação das empresas, foi utilizado basicamente o ranking da revista Exame, publicado anualmente sob o título "Maiores e melhores do ano". Após a seleção das empresas, foram então identificados os nomes dos principais diretores executivos das indústrias listadas. O Quadro 1 pode elucidar melhor esse processo.

\section{QUADRO 1 - IDENTIFICAÇÃO DO GRUPO-ALVO DA PESQUISA}

\begin{tabular}{|l|c|c|c|}
\hline & ranking EXAME & Seleção das indústrias & Titular da posição de presidente, CEO e diretor Geral \\
\hline 1 & Empresa A & Industria - Empresa B & Presidente (Industria B) \\
2 & Empresa B & Industria - Empresa C & CEO (Industria C) \\
3 & Empresa C & Industria - Empresa F & Presidente America Latina (Industria F) \\
4 & Empresa D & Industria - Empresa H & $\ldots$ \\
5 & Empresa E & $\ldots$ & $\ldots$ \\
6 & Empresa F & $\ldots$ & $\ldots$ \\
7 & Empresa G & $\ldots$ & $\ldots$ \\
\hline
\end{tabular}

FONTE: Os autores.

6 O conceito de carreira sem fronteiras propõe novas formas
de atuação e interação dos atores em um modelo onde estes
transitam livremente entre diferentes organizações, adquirindo
competências que os permitem atuar em contextos diferentes,
não estando mais vinculados à identidade de um empregador,
corporação ou culturas locais. O profissional pode construir sua carreira internacionalmente, estando livre dos limites geográficos. Interligada à questão profissional, a ideia de carreiras sem fronteiras está pautada na realização do próprio individuo, expandindo-a para além da vida profissional (ARTHUR, HALL \& LAWRENCE, 1989). Esse conceito traz uma visão contraditória à compreensão de carreira em uma perspectiva sociológica. 
Após a identificação do grupo-alvo de estudo, iniciou-se a segunda fase de exploração, ou seja, o levantamento de variáveis relacionadas às empresas e relacionadas à origem social, qualificação e trajetória profissional dos executivos identificados. As variáveis dependentes e independentes com relação às empresas e aos executivos podem ser vistas no Quadro 2, a seguir.

QUADRO 2 - VARIÁVEIS RELACIONADAS À EMPRESAE AOS EXECUTIVOS

\begin{tabular}{|c|c|}
\hline Indicadores organizacionais & Características \\
\hline Faturamento/Vendas & \$ 0, \$ $10000, \$ 100000$ etc. \\
\hline Ano de fundação da empresa & $1900,1920,2000$ etc. \\
\hline Número de funcionários & 2 000, 8 000, 17000 etc. \\
\hline Ramo/setor econômico & $\begin{array}{l}\text { Indústria de energia, automobilística, de mineração, } \\
\text { alimentícia etc. }\end{array}$ \\
\hline Estrutura proprietária & $\begin{array}{l}\text { Particular, particular de capital estrangeiro, estatal } \\
\text { (participação do Estado em \%) etc. }\end{array}$ \\
\hline Indicadores pessoais e profissionais & Características \\
\hline \multicolumn{2}{|c|}{ Dados Pessoais e Origem Social } \\
\hline Ano de nascimento & $1945,1950,1955$ etc. \\
\hline Sexo & Masculino, feminino. \\
\hline Estado civil & Solteiro, casado, divorciado etc. \\
\hline Posição atualmente ocupada & Presidente, CEO, vice-presidente, presidente e CEO, etc. \\
\hline Local de nascimento & Brasil, Alemanha, Espanha, Chile etc. \\
\hline Local onde cresceu & Brasil, Alemanha, Espanha, Chile etc. \\
\hline Formação educacional e acadêmica dos pais & $\begin{array}{l}\text { Educação básica, média, curso profissionalizante, curso } \\
\text { universitário, mestrado, doutorado etc. }\end{array}$ \\
\hline \multicolumn{2}{|l|}{ Profissão exercida pelos pais } \\
\hline Formação educacional e acadêmica dos avos & $\begin{array}{l}\text { Educação básica, média, curso profissionalizante, curso } \\
\text { universitário, mestrado, doutorado etc. }\end{array}$ \\
\hline \multicolumn{2}{|l|}{ Profissão exercida pelos avós } \\
\hline \multicolumn{2}{|c|}{ Qualificação } \\
\hline Formação acadêmica e titulação & Bacharel, Mestre, Ph.D, sem formação universitária etc. \\
\hline Área de formação/curso universitário & Ciências Naturais, Engenharia, Direito, Economia etc. \\
\hline Instituição de ensino & USP, UFPR, FGV, etc. \\
\hline MBA & Sim, não. Nome do país e instituição de ensino \\
\hline $\begin{array}{l}\text { Permanência no exterior durante a } \\
\text { formação acadêmica ( } \geq 1 \text { ano) }\end{array}$ & Sim, não. Nome do país e instituição de ensino \\
\hline \multicolumn{2}{|c|}{ Carreira e Trajetória Profissional } \\
\hline Tempo de permanência na atual posição (anos) & $0,1,2,3,4,5$ etc. \\
\hline Tempo de inserção na empresa atual (anos) & $0,1,2,5,10,20$ etc. \\
\hline Número de vezes que mudou de empresa & $0,1,2,3,4,5$ etc. \\
\hline $\begin{array}{l}\text { Número de vezes que mudou de ramo } \\
\text { ou setor econômico }\end{array}$ & $0,1,2,3,4,5$ etc. \\
\hline $\begin{array}{l}\text { Número de vezes que mudou de área } \\
\text { de trabalho }\end{array}$ & $0,1,2,3,4,5$ etc. \\
\hline $\begin{array}{l}\text { Número vezes que mudou de conglomerado } \\
\text { empresarial }\end{array}$ & $0,1,2,3,4,5$ etc. \\
\hline $\begin{array}{l}\text { Permanência no exterior para atividades } \\
\text { profissionais }(\geq 1 \text { ano) }\end{array}$ & Tempo e número de permanências. \\
\hline
\end{tabular}

FONTE: Os autores. 
O método life course analysis consiste em um método normalmente utilizado pelas Ciências Sociais para a investigação e análise da biografia e da trajetória de determinados grupos sociais, e tem como objetivo investigar a estrutura social, assim como pontos de inflexões sociais em uma determinada sociedade estudada. Segundo Sackmann (2007) todo indivíduo tem uma trajetória e cada um pode muda-la por engajarse e estabelecer novos objetivos a serem alcançados ao longo da vida. Esta dinâmica pode ser identificada e controlada através de métodos empíricos, os quais permitem levantar as variedades e contradições dos eventos sociais (idem).

As pesquisas de life course analysis permitem não só a identificação e a compreensão da dinâmica e momentos de inflexão social, mas também que se investigue temas como mobilidade social e profissional, trajetórias escolhidas durante a formação profissional e construção da carreira, ciclo de vida familiar etc. (MAYER, 1990). A trajetória de vida é compreendida aqui como resultado de influências econômicas, politicas e culturais, processo de socialização, bem como de escolhas individuais (idem). Além disso, esse método permite o trabalho com grande número de dados, o que pode acrescentar maior validade quantitativa para a pesquisa.

A análise da prosopografia orienta-se pela interpretação da "história" individual de cada ator estudado dentro de um grupo, mas é considerada como uma sequência de eventos que possuem uma dimensão coletiva e que podem mudar o status social de um dado corte. Longitudinalmente, as mudanças nas trajetórias individuais estudadas de um grupo definido, são examinadas por meio de diferentes variáveis dependentes e independentes. A mudança no status social de um indivíduo é primeiramente comparada com as mudanças, ocorridas ou não, com os outros atores incluídos no corte. Assim, as diferenças individuais não devem tornar-se o foco dos estudos, assim também como não podem ser compreendidas isoladamente por meio desse método (KLUGE \& KELLE, 2001).

No caso aqui estudado, a life course analysis contribui para o estudo da mobilidade internacional e as mudanças nos padrões de carreira da elite econômica brasileira e, em um segundo momento, para a análise da mobilidade social da chamada elite econômica brasileira, uma vez que os dados sobre a origem social contribuem para a compreensão dos mecanismos de recrutamento e da reprodução social do grupo estudado.

\section{BRAIN CIRCULATION}

Como mencionado anteriormente, o processo de globalização levaria à emergência de uma elite global, ou seja, a formação de um pequeno grupo de grande influência político-econômica (SKLAIR, 2001). Esse processo seria fomentado pelo acentuado processo de transnacionalização das organizações. Grandes corporações estariam adquirindo um papel e um nível de influência cada vez maior na sociedade atual, durante este último século (LOPEZ-RUIZ, 2004). Isso poderia ser compreendido como consequência da globalização da economia, que faria com que empresas transnacionais ganhassem cada vez mais significado não somente na economia mundial, mas também no estilo de vida e trabalho da sociedade contemporânea (BECK, 1997; SKLAIR, 2001; LOPEZ-RUIZ, 2004). A ideia até então dominante baseada na existência de diferentes sociedades divididas em Estados-Nações passa a ganhar um novo elemento: sua integração transnacional. Isso consiste na ideia de um novo espaço social, no qual fronteiras político-geográficas, assim como culturais, passariam a desempenhar um papel secundário, não somente relacionado a trocas de dinheiro e capital entre os países, mas também pertinentes a decisões políticas e ainda a temas como o do livre deslocamento geográfico e aqui especificamente da mobilidade internacional dos atores sociais.

Diante disso, tanto corporações como indivíduos poderiam atuar e influenciar o meio social além das suas fronteiras regionais e nacionais. Este contexto seria de certa forma a mola propulsora para a emergência de uma classe pós-moderna formada não somente por corporações transnacionais, mas também por governantes, profissionais liberais, elites de consumo e profissionais altamente capacitados, como top managers e executivos da alta gerência, atuantes na sociedade global. Sendo assim, tal grupo participaria de importantes decisões de efeito para além de sua sociedade local, ou seja, de efeito de escala global (SKLAIR, 1991; 2001). Nas palavras do próprio autor, a "transnacional capitalist class" pode conectar-se com membros de várias regiões do mundo e fazer parte de importantes decisões globais.

Pohlmann e Bär (2009) procuram desmistificar tais pressupostos. Mesmo concordando que o processo de globalização pode significar para muitos um aumento da insegurança decorrente da crescente concorrência profissional e das incertezas relacionadas aos rumos tomados com relação a formação profissional, a globalização pode no entanto, também trazer consigo novas chances, assim como novas possibilidades de ascensão social e mobilidade internacional (POHLMANN, 2008; POHLMANN \& BÄR, 2009).

Observando alguns estudos a respeito da mobilidade internacional de estudantes pode-se constatar claramente uma tendência com relação ao aumento do deslocamento internacional de pessoas, 
neste caso, do grupo estudantil. Com relação a isso mostram os dados estatisticos a respeito do deslocamento internacional de estudantes no mundo, mostram um crescente aumento da mobilidade internacional deste grupo nas ultimas décadas. Pohlmann e Bär (2009a) identificaram em seus estudos que estudantes alemães estão entre os primeiros no grupo de países europeus que mais enviam estudantes para o exterior. Em outras palavras, os estudantes alemães são os que mais buscam uma formação complementar no exterior, por meio de estágios, intercâmbios universitários, cursos de línguas etc.

Em termos gerais, os dados estatísticos sobre o deslocamento internacional de estudantes evidenciam a procura por uma formação acadêmica e complementar em outro país, não se trata de fenômeno somente da sociedade alemã. Pode-se dizer que se trata de um fenômeno mundial, o qual também passa a ser fomentado por instituições de apoio ao ensino e pesquisa (ALMEIDA et alii, 2004). Olhando pela pespectiva dos estudantes, poder-se-ia pensar que estes estariam buscando, por meio de trocas, estágios, intercâmbios e cursos no exterior, melhorar suas chances diante da concorrência no mercado de trabalho em um mundo globalizado, assim legitimando, em seu curriculum vitae, o desenvolvimento de uma "competência internacional" sob o título de "experiência internacional".

A Tabela 1, a seguir, mostra os países que mais recebem e enviam estudantes para formação acadêmica no exterior. Diante desses dados, EUA, Reino Unido, França, China, Austrália, Alemanha, Canadá e Japão, respectivamente, são os países que mais recebem estudantes estrangeiros anualmente, embora não sejam necessariamente os países que mais mandam estudantes para o exterior. $\mathrm{O}$ maior número de estudantes internacionais é, respectivamente, de origem chinesa, indiana, coreana, americana, marroquina, argeliana, japonesa, malesia, turca, russa e tailandesa.

TABELA 1 - CIRCULAÇÃO INTERNACIONAL DE ESTUDANTES

\begin{tabular}{|l|c|c|c|}
\hline País Anfitrião & $\mathbf{2 0 0 9}$ & $\mathbf{2 0 1 0}$ & Países de Origem \\
\hline EUA & 690923 & 723277 & China, Índia, Coreia do Sul \\
Reino Unido & 415585 & 455600 & China, Índia, EUA \\
França & 266448 & 283621 & Marrocos, China, Argélia \\
China & 238184 & 265090 & Coreia do Sul, EUA, Japão \\
Austrália & 253717 & 258827 & China, Índia, Malásia \\
Alemanha & 244766 & 252032 & Turquia, China, Rússia \\
Canadá & 161679 & 174760 & China, Índia, Coreia do Sul \\
Japão & 132720 & 141774 & China, Coreia do Sul, Taiwan \\
\hline
\end{tabular}

FONTE: The Open Doors Report on International Educational Exchange, 2011.

O Gráfico 1 evidencia o crescimento da circulação internacional de estudantes nas últimas décadas. Entre os anos de 1975 e 2009 houve um aumento significativo do deslocamento internacional de estudantes no mundo, um crescente aumento da mobilidade internacional poderá chegar, no ano de 2020 , a 5,8 milhões de estudantes.

\section{GRÁFICO 1 - ESTIMATIVA DE CRESCIMENTO DA CIRCULAÇÃO INTERNACIONAL DE ESTUDANTES NO MUNDO}

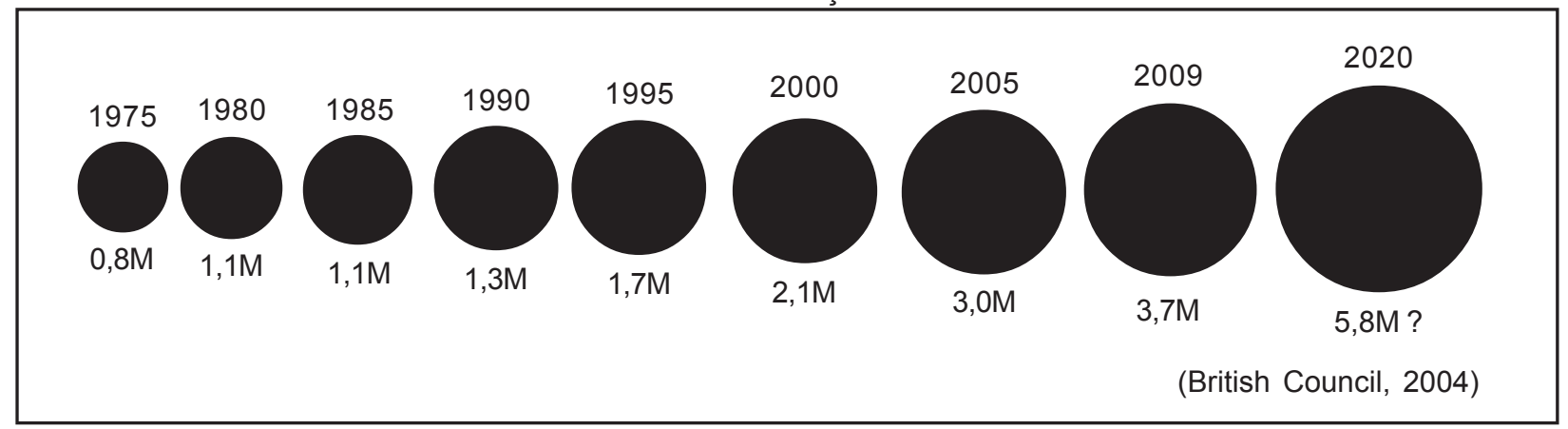

FONTE: The Open Doors Report on International Educational Exchange, 2011. 
Com relação ao Brasil, também se pode observar $\mathrm{o}$ fomento com relação à mobilidade internacional de estudantes. O programa Ciência Sem Fronteiras, por exemplo, lançado em 2012, envolvendo a Capes e o $\mathrm{CNPq}$, é voltado para o envio de estudantes brasileiros de graduação e pós-graduação ao exterior e a vinda de estudantes estrangeiros para o Brasil. Segundo dados do Ministério da Educação, esse programa tem como meta, a ser atingida até 2015, a conceção de 101000 bolsas para estudantes brasileiros que pretendem estudar no exterior. As bolsas estão distribuidas em diferentes modalidades de ensino superior para cursos de graduação e pós-graduação. Além disso, a Capes tem desenvolvido parcerias com outras instituições como: $\mathrm{DAAD}^{7}, \mathrm{BMBF}^{8}$ etc. para o oferecimento de bolsas de estudos, sem vinculo direto com o programa Ciências Sem Fronteiras. Entre os países que mais recebem brasileiros segundo dados do Governo Federal são respectivamente França, EUA, República Tcheca e Alemanha (BRASIL. ME, 2013). Como se pode perceber, o processo de internacionalização da formação profissional parece não ser unilateral, uma vez que não se restringe somente à busca de estudantes por cursos de formação profissional no exterior, mas também, segundo Almeida et alii (2004), esse processo de internacionalização das competências acadêmicas parece ser de fato fomentado por instituições de ensino ou instituições vinculadas à instituições de ensino superior (idem).
A mobilidade internacional entre estudantes parece não ser um mito da globalização, uma vez que, como visto acima, os dados estatísticos mostram claramente o aumento do deslocamento internacional desse grupo. Embora se possa constatar um crescente processo de internacionalização na formação de jovens estudantes, ainda não se pode saber o quanto destes permanecem no país estrangeiro e desenvolvem lá sua carreira profissional.

Pohlmann e Bär (2009), em suas pesquisas sobre boderless career, investigaram o fenômeno do brain circulation $^{9}$ de profissionais altamente capacitados na Alemanha, entre eles presidentes e diretores gerais, no setor industrial, e médicos diretores gerais de grandes hospitas ${ }^{10}$. Seus estudos mostram que o brain drain está muito aquém se comparado com a abrangência do discurso político e medial alemão sobre o assunto. Os dados da Tabela 2 permitem visualizar o que Pohlmann e Bär (idem) procuram evidenciar. Esses dados mostram que o número total estrangeiros que ocuparam posições executivas na Alemanha, no ano de 2010, representa somente 7,5\% do total de top managers ocupando essas posições. No ano de 2011, esse número sofreu ainda uma leve regressão, passando a representar somente $6,8 \%$ do total de top e middle managers atuantes em empresas alemãs (idem).

TABELA 2 - ESTRANGEIROS EM ALTOS CARGOS DE DIRETORIA E GERÊNCIANAALEMANHA

\begin{tabular}{|l|c|c|c|c|}
\hline & Alemanha & $\begin{array}{c}\text { Oriundos } \\
\text { de paises } \\
\text { estrangeiros }\end{array}$ & $\begin{array}{c}\text { Oriundos } \\
\text { de países } \\
\text { europeus }\end{array}$ & $\begin{array}{c}\text { Oriundos } \\
\text { de outras } \\
\text { regiões }\end{array}$ \\
\hline \multicolumn{7}{|c|}{ No ano de 2010 } \\
\hline Diretor Executivo/Empresário & 777000 & $8,3 \%(65000)$ & $6,9 \%$ & $1,4 \%$ \\
Chefe de divisão & 482000 & $6,4 \%(31000)$ & $5,6 \%$ & $0,8 \%$ \\
Total & 1249000 & $7,5 \%(95000)$ & $6,3 \%$ & $1,2 \%$ \\
\hline \multicolumn{7}{|c|}{ No ano de 2011 } \\
\hline Diretor Executivo/Empresário & 893000 & $8 \%(72000)$ & $6,6 \%$ & $1,4 \%$ \\
Chefe de Divisão & 621000 & $5,3 \%(33000)$ & $4,5 \%$ & $0,8 \%$ \\
Total & 1514000 & $6,8 \%(104000)$ & $5,7 \%$ & $1,1 \%$ \\
\hline
\end{tabular}

FONTES: Pohlmann e Bär (2009) e Mikrozensus (DESTATIS, 2013).

\footnotetext{
7 DAAD: Deutscher Akademischer Auslandsdienst [Serviço Alemão de Intercâmbio Acadêmico]. Disponível em: http:// www.daad.org.br/pt/. Acesso em: 12.ago.2013.

8 BMBF: Bundesministerium für Bildung und Forschung [Ministério da Educação e Pesquisa]. Disponível em: http:// www.bmbf.de. Acesso em: 12.ago.2013.

9 Esse termo foi primeiramente utilizado Chalamwong (2005) para descrever o deslocamento de profissionais altamente
}

qualificados da Inglaterra para os Estados Unidos. O termo refere-se principalmente à alta mobilidade desses profissionais entre países industrializados. Neste caso, referindo-se à Alemanha, o termo refere-se ao número de profissionais altamente qualificados que emigram ou imigram para a Alemanha.

10 Serão tratados aqui somente os dados referentes aos diretores gerais e presidentes de indústrias. Os dados quantitativos, relacionados à area da Medicina, não serão abordados neste artigo. 
Além dos dados do Mikrozensus apresentados na Tabela 2, foi investigado, nas pesquisas de Pohlmann (2009b), o número de top managers alemães, entre os anos de 2005 e $2008^{11}$, que dirigiam grandes empresas em diferentes países membros da Organização para a Cooperação e Desenvolvimento Econômico (OECD), como Japão, Coréia do Sul, China e Índia. $\mathrm{O}$ resultado de seus estudos demostraram que, no top management das indústrias estudadas, não havia a presença de nenhum executivo alemão (idem). Em outras palavras, não foi identificado nenhum executivo alemão atuando como presidente ou diretor geral entre as 100 maiores empresas dos países acima citados (POHLMANN, 2009b; POHMANN \& BÄR 2009). Michel Hartmann, outro pesquisador alemão sobre a formação e reprodução de elites econômicas, comprova que a circulação internacional de profissionais altamente qualificados mostra-se significativamente pequena na França, Inglaterra e EUA, o que demonstra que a dinâmica de brain circulation parece ser bem restrita quando referida a executivos atuantes em altas posi- ções administrativas e gerenciais (HARTMANN, 2007).

Com relação ao processo migratório entre países da América do Sul e EUA, pode-se perceber, por meio da análise de dados estatísticos, que a ocupação de altas posições na economia por estrangeiros não se mostra muito diferente dos resultados obtidos nos estudos de Pohlmann (2009a; 2009b) e Pohlmann e Bär (2009). Isso pode ser observado mais de perto com os dados apresentados na Tabela 3, relacionados ao deslocamento internacional de profissionais de países sul-americanos para os EUA. Tais números mostram que a porcentagem de brasileiros e sulamericanos em geral trabalhando nos EUA, na área administrativo-financeira, é significativamente reduzido, exatamente $7 \%$, comparado com o percentual de estrangeiros que exercem outras funções profissionais. Além disso, por meio dos dados do MPI (2007), não se pode afirmar com exatidão quantos brasilieros que atuam na área administrativo-financeira ocupam de fato uma alta posição gerencial.

TABELA 3 - IMIGRANTES NOS ESTADOS UNIDOS (ACIMADE 16 ANOS) E SUA OCUPAÇÃO PROFISSIONAL

\begin{tabular}{|c|c|c|c|c|c|c|c|c|c|c|c|c|}
\hline & $\begin{array}{l}\overline{\widetilde{J}} \\
\text { ○ }\end{array}$ & 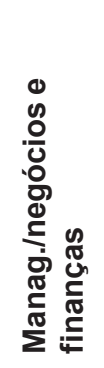 & $F$ & 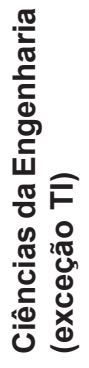 & 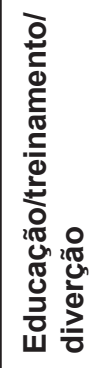 & $\begin{array}{l}\frac{0}{0} \\
\stackrel{0}{\pi} \\
\text { ஸे }\end{array}$ & 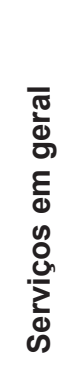 & $\begin{array}{l}\frac{n}{0} \\
\frac{\pi}{0} \\
\frac{5}{0} \\
\end{array}$ & 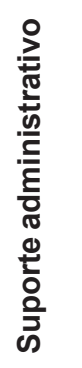 & 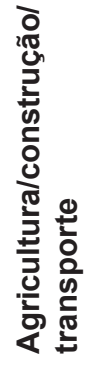 & 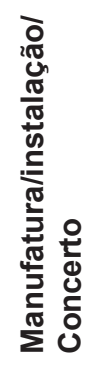 & 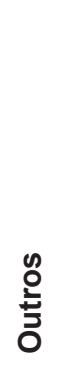 \\
\hline $\begin{array}{l}\text { América } \\
\text { do Sul } \\
\text { (Total) }\end{array}$ & 1080071 & $8 \%$ & $2 \%$ & $2 \%$ & $6 \%$ & $4 \%$ & $26 \%$ & $11 \%$ & $11 \%$ & $18 \%$ & $11 \%$ & $3 \%$ \\
\hline Colombia & 217356 & $8 \%$ & $2 \%$ & $3 \%$ & $6 \%$ & $4 \%$ & $26 \%$ & $11 \%$ & $13 \%$ & $12 \%$ & $13 \%$ & $3 \%$ \\
\hline Brasil & 201129 & $7 \%$ & $2 \%$ & $2 \%$ & $5 \%$ & $2 \%$ & $34 \%$ & $8 \%$ & $8 \%$ & $23 \%$ & $7 \%$ & $2 \%$ \\
\hline Peru & 163316 & $7 \%$ & $1 \%$ & $2 \%$ & $6 \%$ & $4 \%$ & $28 \%$ & $12 \%$ & $11 \%$ & $15 \%$ & $12 \%$ & $2 \%$ \\
\hline Ecuador & 163049 & $3 \%$ & $1 \%$ & $1 \%$ & $3 \%$ & $2 \%$ & $25 \%$ & $8 \%$ & $9 \%$ & $28 \%$ & $17 \%$ & $4 \%$ \\
\hline Venezuela & 74741 & $14 \%$ & $2 \%$ & $5 \%$ & $11 \%$ & $2 \%$ & $19 \%$ & $15 \%$ & $13 \%$ & $10 \%$ & $6 \%$ & $3 \%$ \\
\hline
\end{tabular}

FONTE: MPI (2007).

Os dados atuais levantados na pesquisa "O novo espírito do capitalismo no top management" (POHLMANN, 2011b) têm confirmado um número muito restrito de brasileiros executivos atuando como presidentes e/ou diretores gerais de grandes indústrias

\footnotetext{
11 Uma reinvestigação desses dados está sendo realizado em sua atual pesquisa "O novo espírito do capitalismo no top management" (POHLMANN, 2011a).
}

nos diferentes países estudados ${ }^{12}$. Seu total não representaria 3\% do sampling. Quando analisado o número de estrangeiros no Brasil que assumem posições gerenciais, os números indicam a permanência de 21 presidentes e diretores gerais liderando 21

\footnotetext{
12 Entre os países estudados estão Alemanha, Suíça, Áustria, Inglaterra, EUA, Japão, China, Coreia do Sul, India, Hong Kong, Brasil e Argentina.
} 
empresas listadas entre as 100 maiores indústrias no Brasil. Em um primeiro momento, pode-se pensar em um processo de internacionalização do top management nas indústrias brasileiras. Todavia, entre as 100 maiores empresas do setor industrial situadas no Brasil, 49 são de capital estrangeiro. Isso representa $48 \%$ das empresas estudadas, um número relativamente alto se comparado com os outros países investigados nesta pesquisa. Sendo assim, os 21 executivos estrangeiros estão na presidência de filiais multinacionais e/ou transnacionais no Brasil. O mesmo acontece com os poucos executivos brasileiros no exterior. Estes estão em via de regra a serviço de empresas genuinamente brasileiras de atuação internacional (idem). Tais dados podem indicar tendências de internacionalização na trajetória profissional de executivos, mas ainda não demonstra características que indicariam a existência de borderless career.

Os executivos estudados, no Brasil, apresentam em sua formação acadêmica um alto grau de internacionalização. Cerca 50\% deles fizeram parte de sua formação acadêmica e/ou acadêmica complementar no exterior, em especial parte de pós-graduações. No entanto, se somente forem consideradas permanências no exterior acima de um ano, o número cai para $22 \%$. No que diz respeito à carreira propriamente dita, três quartos dos executivos brasileiros estiveram por no mínimo um ano a trabalho no exterior.

Uma breve análise dos dados apresentados acima, a respeito do movimento migratório de estudantes e da internacionalização da carreira de altos executivos, permite constatar que o tratamento da literatura a respeito do brain circulation demostra dar uma maior ênfase ao tema, quando observado empiricamente. Dessa forma, a ideia de um intenso processo migratório de profissionais altamente capacitados, como propõem as teorias da globalização, não parece ter consistência empírica. Embora possa se observar um crescente deslocamento internacional de estudantes, o mesmo não pode ser observado entre os altos executivos. A crescente circulação internacional parece estar bem restrita quando se trata de profissionais altamente qualificados, e, neste caso, em posições de alta gerência.

Carreiras sem fronteiras ou internacionais parecem ocorrer na prática dentro dos "limites" das próprias empresas, por meio de sua própria dinâmica de expatriação. O processo de internacionalização parece muito mais ocorrer por meio da formação acadêmicocomplemantar e/ou de períodos de permanência em unidades ou filiais da empresa no exterior, em geral organizados pela própria empresa, do que pelo desenvolvimento de uma carreira internacional propriamente dita, que se justifica pelo recrutamento internacional de executivos por diferentes empresas de diferentes nacionalidades. Diante dos dados apresentados, não existem indícios do desenvolvimento e da continuação de carreiras transnacionais, mas sim um processo de internacionalização leve, descrito por Pohlmann e Bär (2009) como light internationalization, discutido na próxima seção.

\section{PROFISSIONAL DE CARREIRA X CARREIRA INTERNACIONAL}

Um artigo da revista Exame (ESTAMOS NA ERA DO EXECUTIVO INFIEL, 2013) traz que de cada dez executivos das maiores companhias no Brasil, quatro pretendem mudar de empresa nos próximos dois anos. Isso indicaria uma grande flutuação de trabalho nesse meio, caracterizada por constantes trocas de empresa ou conglomerado. Mas será que seria esse o padrão de carreira do executivo industrial brasileiro, marcado por constantes trocas de setores e empresas, ou ainda envolvendo steps no exterior?

Como discutido acima, a globalização funcionaria como uma mola impulsionadora do surgimento de borderless career para altos executivos. Esse grupo passaria não somente a desfrutar de previlégios, como a escolha por onde viver e trabalhar, mas também participariam de importantes decisões políticoeconômicas de abrangência internacional. Tudo isso porque os limites político-geográficos não passariam mais a desempenhar papel algum (BECK, 1997; SKLAIR, 2001). Esse novo paradigma de espaço político-geográfico, conduziria a uma nova visão de espaço social, a qual implicaria, entre outros, o desenvolvimento de novos padrões de carreira, deixando de ser orientadas por normas e valores nacionais e culturais. Beck (1997) e Sklair (2001) afirmam que esse processo seria desencadeado e fomentado pelas organizações transnacionais por meio de seu processo de produção e sua atividade comercial e financeira global, acelerando com isso o processo de recrutamento internacional de profissionais altamente qualificados e, consequentemente, a formação de carreiras transnacionais.

Pohlmann (2009b; 2011b) identificou que embora experiências internacionais sejam bem vindas no momento de contratação, estas não parecem desempenhar um papel determinante para a continuação da carreira dentro da organização, principalmente no que se refere à ocupação de posições superiores (top positions). Em via de regra, chegam às posições mais altas aqueles que fazem sua carreira dentro da empresa, ou seja, profissionais com muitos anos de casa, também chamados de "profissionais de carreira" (POHLMANN 2008; 2009a; 2011b; POHLMANN \& BÄR 2009). 
A preferência por profissionais de carreira não exclui automaticamente a sua bagagem internacional, adquirida durante a trajetória profissional. Esta pode, por sua vez, alavancar em alguns momentos o desenvolvimento da carreira dentro da organização. Para os atuais top managers investigados, as permenências no exterior em via de regra aconteceram a serviço da própria empresa. Elas não estiveram vinculadas a mudanças de organização, mas sim a uma temporária expatriação do profissional em uma unidade internacional da empresa. Dessa forma, tais profissionais haviam iniciado sua carreira e desenvolvido grande parte dela na sede da organização, localizada em seu país de origem, antes de assumirem postos em unidades no exterior e, portanto, a posição de top manager. Assim, pode-se verificar, em sua biografia, que suas permanências no exterior foram em sua maioria de curta duração e realizadas em unidades subsidiárias da empresa em outros países. Pohlmann e Bär (2009) descrevem essa dinâmica de expatriação como uma forma de internacionalização leve na carreira de altos executivos, em suas palavras, light internationalization (idem). Uma vez que a internacionalização da carreira de top managers parece, por via de regra, ocorrer dentro dos limites da própria organização, pode-se dizer que o sistema de carreira desse grupo parece estar orientado por valores e normas culturais. Isso indicaria que mesmo diante da globalização parece predominar um modelo de carreira pautado em normas e valores locais, ou, ainda, nacionais.

Pohlmann (2009a) identificou ainda que top managers de multinacionais alemãs comumente trabalharam a maior parte do tempo de sua carreira na sede da empresa, como apresentado acima. Os executivos alemães que permanecem longos períodos no exterior, gerenciando empresas subsidiárias alemãs, acabam por ter menores chances de atigir posições no top managemet na sede da organização. Muitas vezes, os altos salários e benefícios oferecidos são considerados como uma forma de conpensação, por terem suas chances de atingir o top management diminuídas pelo fato de terem passado muito tempo fora da sede da organização (POHLMANN, 2008; 2009a; 2011b; POHLMANN \& BÄR, 2009). Isso mostra a existência de um modelo dominante de padrão de carreira entre os top managers das indústrias alemãs, caracterizado pela predominância de carreiras domésticas e preferência por profissionais insiders. Sociologicamente, pode se compreender esse fenômeno como uma preferência por profissionais com longo processo de socialização dentro da organização, o que garantiria uma forte identificação do profissional com os valores e normas da empresa e, consequentemente, um vínculo estável de lealdade e compromisso.
Os dados recentemente levantados a respeito da biografia e trajetória dos executivos brasileiros mostram que estes também apresentam, em sua maioria, um longo tempo de socialização dentro da empresa, em média 22,67 anos, sugerindo que o tempo de inserção dos executivos brasileiros dentro da organização desempenha um papel importante para a sua ascensão ao top management (POHLMANN, 2011a). Outro aspecto importante está relacionado ao número de trocas de organização dos executivos brasileiros ao longo de sua carreira. Os resultados mostraram que a grande maioria dos executivos estudados trocou de empresa no máximo uma vez no decorrer de sua vida profissional, considerando que nos primeiros cinco anos podem ocorrer algumas trocas de trabalho até que o executivo estabeleça-se em uma função e organização de seu interesse (POHLMANN, 2009b; POHLMANN \& BÄR, 2009).

Comparando os resultados da pesquisa desenvolvida no Brasil e os resultados dos estudos até então realizados na Alemanha, pode-se afirmar que o modelo dominante de carreira nos dois países estudados parece ser o modelo de carreira doméstica. O tempo de inserção do profissional alemão dentro da organização é, em média, de 16 anos ${ }^{13}$. Como visto acima, a média de tempo de trabalho do executivo brasileiro é de 22,67 anos (POHLMANN, 2009b; 2011b; 2011a). Além disso, a porcentagem de executivos alemães que mudaram de organização no máximo uma vez ao longo de sua carreira consiste em $76,7 \%$, enquanto a porcentagem de executivos brasileiros é de $61,6 \%$.

Outro aspecto muito importante a ser ressaltado a respeito da internacionalização do top management no Brasil consiste no número de top managers estrangeiros atuantes no Brasil. Por meio dos dados recentemente levantados (POHLMANN, 2011a), pode-se verificar a existência de 21 executivos estrangeiros entre os 100 top managers estudados. A princípio, esses dados poderiam levar a conclusões a respeito de um processo mais intenso de internacionalização da carreira de altos executivos, podendo ser observado no Brasil. No entanto, se tais dados forem analisados mais de perto, percebe-se que se trata mais uma vez de uma dinâmica de expatriação organizada pela própria empresa. Essa dinâmica pode ser observada com mais precisão na Tabela 4.

13 Dados recentemente levantados para a pesquisa "O novo Espirito do Capitalismo no Top-Management". O tempo médio de 16 anos refere-se ao tempo de insercao organizacional dos CEOs e presidentes executivos das 100 maiores industrias alemas. 
TABELA 4 - INTERNACIONALIZAÇÃO DO TOP MANAGEMENT NO BRASIL

\begin{tabular}{|lccc|}
\hline & Brasileira & Estrangeira & Total \\
\hline Nacionalidade & 81 & 21 & 102 \\
\hline & $\begin{array}{c}\text { Gerenciando indústrias } \\
\text { brasileiras }\end{array}$ & $\begin{array}{c}\text { Gerenciando indústrias } \\
\text { multinacionais }\end{array}$ & Total \\
\hline Top-Manager brasileiros & 54 & 27 & 81 \\
Top-Manager estrangeiros no Brasil & 0 & 21 & 21 \\
\hline
\end{tabular}

FONTE: Pohlmann (2011a).

De acordo com os dados apresentados na Tabela 4, não há evidências de atuação de executivos estrangeiros em empresas genuinamente brasileiras, ao contrário, todos os 21 executivos estrangeiros atuam em empresas multinacionais no Brasil. Com isso, pode-se dizer que eles estão no Brasil a serviço de empresas, cuja sede está localizada em seu país de origem. Um bom exemplo para essa dinâmica seria a de top managers alemães que frequentemente estão no Brasil como presidente de empresas alemãs. Por mais que o Brasil seja um país com uma grande atuação de indústrias internacionais no seu mercado interno, não se pode falar de uma internacionalização gerencial dessas indústrias, uma vez que a gerência parece permanecer orientada por modelos nacionais de carreira (idem).

Diante dos dados apresentados acima se pode concluir que, no Brasil, existe um modelo dominate de carreira de executivos que consiste em um longo período de inserção dentro da organização e relativamente poucas trocas de trabalho durante a trajetória. Essas características indicam um modelo de carreira doméstica, ou seja, a trajetória profissional acaba acontecendo dentro de uma organização que orienta e determina os caminhos a serem seguidos ao longo da carreira. Carreiras domésticas são via de regra orientadas por normas e valores nacionais, o que também pode ser observado com relação a nacionalidade dos CEOs e a nacionalidade das empresas lideradas por eles no Brasil. Tais resultados contradizem os pressupostos das teorias da globalização, que afirmam existirem carreiras transnacionais como efeito do processo de globalização (POHLMANN, 2009a; 2011b; POHLMANN \& BÄR, 2009).

\section{RECRUTAMENTO INTERNACIONAL?}

Como discutido nas seções anteriores, a hipótese do surgimento de uma elite econômica transnacional formada por executivos e profissionais altamente qualificados e disputados globalmente pode ser empiricamente revidada. Intimamente ligada a esse discurso da internacionalização do top management está a questão do recrutamento dessa elite econômica
(POHLMANN \& BÄR, 2009). Tais teorias enfatizam o desempenho profissional como um dos requisitos mais importantes para fazer parte desse grupo, desconsiderando, dessa forma, correlações com outras possíveis variáveis, como a origem social, educação formal, entre outras. A preferência por carreiras domésticas, como discutido no item anterior, não é o único aspecto que conduz à idéia de que outros critérios também desempenham um papel importante no recrutamento de executivos da alta administração (POHLMANN, 2009a).

Diferenças e similaridades, não só com relação ao padrão de carreira dominante, mas também com os mecanismos de recrutamento de inserção nesse grupo em diferentes sociedades, consistem em um dos principais interesses dos estudos a respeito da formação de elites econômicas. Pohlmann (idem) mostra que na Alemanha, por exemplo, o mecanismo de recrutamento para o top management de corporações transnacionais demonstra estar organizado de tal forma que permite uma reprodução de funções e posições. Isso indica a existência de uma reprodução social, observada por meio da função exercida pelos pais e avós dos executivos estudados até o momento. Sendo assim, pode-se observar que a maioria dos executivos alemães vem de famílias em que os pais e avós tinham profissões na área econômica.

$\mathrm{O}$ recrutamento funcional parece ser determinado ainda muito cedo, ou melhor, antes mesmo do início da trajetória profissional. Isso demonstra que a escolha por cursos acadêmicos específicos pode significar uma primeira seleção, entre outras futuras (POHLMANN 2011b; POHLMANN \& BÄR, 2011). Isso indicaria que determinadas profissões poderiam conduzir a determinadas posições. Esse processo pode ser comprovado pelos estudos de Pohlmann (2009a; 2011b) na Alemanha. Entre os executivos alemães estudados, pode-se observar uma grande representatividade das áreas de Engenharia, Economia e Administração de Empresas. Outro mecanismo de recrutamento dos executivos alemães indica que a atuação profissional em determinados setores e a rede social desenvolvida 
pelo executivo dentro da empresa acabam por desempenhar um papel importantíssimo para se chegar ao top management (POHLMANN \& BÄR, 2011).

$\mathrm{O}$ caminho que levaria ao top management não poderia, de forma alguma, ser investigado sem uma relação com a origem social desse grupo. Sendo assim, os resultados dos estudos de Pohlmann (2009a) e Pohlmann e Bär (2011) mostram que, embora não exista uma representação massiva da alta burgesia alemã - somente $7 \%$-, pode-se perceber que a grande maioria (80\%) dos top managers alemães vem de famílias consideradas burguesas. Diante desses dados, pode-se dizer que, no caso da Alemanha, o recrutamento da elite econômica não se trata de um processo de reprodução da elite propriamente dita. Ao contrário, trata-se muito mais da mobilidade social, relacionada tanto à ascensão quanto ao descenso social (POHLMANN \& BÄR, 2011). Mesmo que os executivos alemães tenham seu caminho para o top management de certa forma preparado por seu grupo social, inclusive pela família, a ocupação de altas posições não demonstra ser determinada pela família. Sendo assim, tratam-se mais de possibilidades de ascensão social existentes na sociedade alemã, que se mostram relativamente grandes (POHLMANN, 2011b).

Os dados recentemente levantados a respeito da biografia e trajetória profissional dos executivos brasileiros parecem demonstrar, assim como na Alemanha, a existência de uma relativa permeabilidade social. Grande parte desse grupo vem de famílias de profissionais liberais, sitiantes, empresários e comerciantes de classe média e média alta. Apenas uma pequena parte desse grupo provém de famílias situadas na chamada alta burguesia, famílias de grandes empresários, latifundiários etc. (POHLMANN, 2011a). No caso do Brasil, as instituições de ensino como a escola e a universidade poderiam desempenhar um papel importante no que diz respeito ao recrutamento da elite econômica. De acordo com os dados, o grupo estudado poderia ser dividido em dois grandes grupos, com relação à instituição de ensino superior frequentada. Enquanto pouco mais de $50 \%$ dos executivos investigados estudaram em universidades federais brasileiras, a outra metade concluiu seu curso acadêmico em universidades e faculdades particulares de boa reputação na área administrativa, como a Fundação Getúlio Vargas (FGV) e a Fundação Dom Cabral (FDC) (idem). Além da escolha pela instituição de ensino superior, pode-se observar também um mecanismo de recrutamento funcional entre os executivos brasileiros. Cerca de $60 \%$ dos top managers investigados concluíram um curso de Engenharia e/ ou um curso na área das Ciências Naturais. O restante de $40 \%$ formou-se em Economia ou Administração. Isso deixa claro o quanto a área de atuação pode interferir no recrutamento da elite econômica brasileira.

Assim como a explicação para o deslocamento internacional de top managers de grandes corporações não pode basear-se somente em critérios econômicos, mesmo que estes sejam também relevantes, a forma de recrutamento da elite econômica não pode estar pautada unicamente em critérios relacionados ao próprio indivíduo, como, por exemplo, seu desempenho profissional. Para uma análise dessa ordem, faz-se necessário que sejam melhor estudados o padrão de carreira e a forma de recrutamento institucionalizados na sociedade do grupo investigado (POHLMANN, 2009a). Diante disso, não é só o modelo dominante de padrão de carreira, o do profissional de carreira, que tem sido intensamente investigado por sociólogos, mas também a forma como esse grupo se reproduz (idem; HARTMANN, 2003).

Do ponto de vista sociológico, explicações que possam determinar a variação entre padrões de carreira e a forma de recrutamento da elite econômica em diferentes sociedades podem ser alcançadas somente por meio da análise de fatores socioestruturais, culturais e também organizacionais, que é o que se pretende investigar (POHLMANN, 2011a).

\section{CONCLUSÕES}

O presente artigo teve como objetivo principal fazer uma análise da internacionalização do top management a partir dos primeiros dados empíricos levantados sobre a biografia e trajetória profissional de top managers brasileiros e, assim, contribuir para as discussões a respeito do surgimento de uma elite econômica global, tema frequentemente discutido pelas teorias da globalização. As análises aqui realizadas tiveram como parâmetro metodológico pesquisas realizadas sobre a Europa, o Leste Asiático e os Estados Unidos. Seus resultados revelam importantes aspectos, tanto a respeito da estrutura social de cada um dos países estudados, como da mobilidade internacional de executivos de alto escalão.

No decorrer deste artigo pode-se perceber claramente uma crescente mobilidade internacional de estudantes de vários países do mundo. Tal movimento vem sendo, contudo, fomentado por instituições de apoio ao ensino e à pesquisa (ALMEIDA et alii, 2004). $\mathrm{O}$ aumento da mobilidade internacional também pode ser percebido em outras formas de movimento social, como, por exemplo, no fluxo migratório profissional, cujo tema pode ser abordado em pesquisas sociológicas voltadas para os fluxos migratórios. No entanto, se observarmos o número de trabalhadores sul-americanos nos Estados Unidos, podemos 
perceber que, embora a quantidade de sul-americanos vivendo e trabalhando nos EUA seja significativa, esse número é muito pequeno quando se trata da ocupação de altas posições administrativas. O mesmo pode ser observado na Alemanha por meio dos dados do Mikrozensus $^{14}$ (DESTATIS, 2013).

Esses dados mostram que, embora algumas teorias descrevem a existência de um alto deslocamento internacional de grupos elitizados, como governantes, executivos etc. e, assim, um crescente processo de internacionalização da gerência de grandes organizações internacionais impulsionado pelo processo de globalização, os dados mostram-nos que essa internacionalização está restrita aos "limites" de tais organizações, ou seja, um processo de light internationalization (POHLMANN \& BÄR, 2009).

Isso nos leva a pensar que, embora as experiências internacionais, mesmo que ainda na fase de formação acadêmica, sejam valorizadas positivamente na busca de um trabalho, elas não parecem ser um critério decisivo para a construção de carreiras gerenciais. Observando os dados levantados no Brasil sobre os top managers brasileiros e das pesquisas realizadas por Pohlmann $(2009 ; 2011 b)$, os executivos trazem, em seu currículo, uma leve internacionalização em sua carreira, ou seja, passam períodos curtos no exterior organizados pela própria empresa. A light internationalization pode ser melhor compreendida quando se observa o constante movimento internacional de profissionais de companhias multinacionais e transnacionais entre suas subsidiárias. No entanto, se as estadias forem muito longas, esses profissionais perdem a chance de assumir posições mais altas na sede da corporação e ainda podem ter dificuldades de recolocação profissional no seu retorno (POHLMANN \& BÄR, 2009). Tais conclusões não nos levam à confirmação do surgimento de mercados internacionais para top managers, uma vez que a internacionalização da carreira trata-se de uma internacionalização leve.

Uma explicação seria o fato de que o padrão de carreira dominante nas organizações dos países estudados consiste no modelo de carreira doméstica,

14 O Mikrozensus é um órgão de pesquisa representativa oficial da Alemanha. O micro-senso (Mikrozensus) existe 1957 e fornece dados sobre a estrutura da população e da situação econômica e social da população alemã. Com informações sobre a vida familiar, mercado de trabalho, agências de emprego e formação profissional, o micro-censo tornou-se uma importante fonte de dados, utilizada desde em estatísticas dos líderes dos parlamentos até em pesquisas acadêmicas. ou seja, do profissional de carreira. Isso nos leva à compreensão de que o padrão de carreira institucionalizado nos países está fortemente ligado a valores e princípios nacionais. Sendo assim, executivos com longo período de socialização dentro da empresa, em seu país de origem, têm maiores chances de chegar à presidência da empresa se comparandos com colegas de trabalho que passaram muito tempo no exterior.

O padrão de carreira está também relacionado ao modo como a elite econômica se reproduz. Diante disso, observou-se que, além da preferência por profissionais de carreira, existe ainda certa primazia por determinadas áreas de formação acadêmica e atuação profissional quando se trata da ocupação de posições no top management. Tanto na Alemanha quanto no Brasil, os dados empíricos mostram que a grande maioria dos diretores executivos das empresas estudadas tem formação acadêmica nas áreas de Engenharia, Economia e Administração de Empresas (POHLMANN, 2011b). Na Alemanha, o recrutamento funcional e setorial ganha ainda um aspecto importante, a formação de uma rede social dentro da empresa, que, por sua vez, permite um impulso indireto na carreira. Com relação ao tempo de inserção do profissional dentro da empresa, pode-se observar que Brasil e Alemanha não apresentam grandes diferenças com relação a isso.

A análise dos padrões de carreira e recrutamento de elites econômicas alemãs e brasileiras permite-nos concluir que em ambos os países, o sistema de carreira está intrinsicamente ligado a valores culturais e nacionais e é corientado pelas organizações. Isso significa que o meio organizacional, por meio das funções e setores percorridos, desempenham um papel importante para se chegar a uma posição de alta gerência. Com isso, o tempo de inserção do profissional dentro da empresa torna-se um elemento muito importante para o seu exito e sua ascensão profissional.

Por fim, podemos concluir, com os dados apresentados, que não pode ser observado o surgimento de mercados internacionais de top managers. Embora essa tese vem sido frequentemente discutida pelas teorias mainstream da globalização, pode ser verificada até o momento por meio de dados empíricos, aqui relacionados a mobilidade internacional de executivos de alto escalão. Enquanto os sistemas de carreira indicarem a reprodução de um status social por meio da ocupação de determinadas posições, os padrões de carreira estarão vinculados a modelos nacionais e não a padrões internacionais. 
Markus Pohlmann (markus.pohlmann@soziologie.uni-heidelberg.de) é Professor de Sociologia na Universidade de Heidelberg (Alemanha).

Elizangela Valarini (elizangela.valarini-seiss@soziologie.uni-heidelberg.de) é Mestranda em Sociologia das Organizações pela Universidade de Heidelberg.

\section{REFERÊNCIAS BIBLIOGRÁFICAS}

ALMEIDA, A. M.; CANÊDO, L. B.; GARCIA, A. \& BITTENCOURT, A. B. (orgs.). 2004. Circulação internacional e formação intelectual das elites brasileiras. São Paulo: Unicamp.

ATTESLANDER, P. 2003. Methoden der empirischen Sozialforschung. Berlin: Gruyter.

ARTHUR, M. B.; HALL, D. T. \& LAWRENCE, B. S. (eds.). 1989. Handbook of Career Theory. New York: University of Cambridge.

BECK, U. 1997. Was ist Globalisierung? Irrtümer des Globalismus - Antworten auf Globalisierung. Frankfurt: Suhrkamp.

BOLTANSKI, L. \& CHIAPELLO, E. 2009. O novo espírito do capitalismo. São Paulo: M. Fontes.

CHALAMWONG, Y. 2005. The Migration of Highly Skilled Asian Workers to OECD Member Countries and its Effects on Economic Development in East Asia. In: FUKASAKU, K.; KAWAI, M.; PLUMMER, M. G. \& TRZECI, A. (eds.). Policy Coherence Towards East Asia. Development Challenges for OECD Countries. Paris: OECD.

DIEKMANN, A. 2005. Empirische Sozialforschung: Grundlagen, Methoden, Anwendungen. Hamburg: Rowohlt.

FRIEDRICHS, J. 1990. Methoden empirischer Sozialforschung. Opladen: VS Verlag für Sozialwissenschaft.

GUNZ, H. P.; EVANS, M. G. \& JALLAND, M. R. 2000. Career Boundaries in a 'Boundaryless' World. In: ARTHUR, M. B.; PEIPERL, M. A., GOFFEE, R. \& MORRIS, T. (eds.). 2000. Career Frontiers: new conceptions of working lives. New York: University of Oxford.

HARTMANN, M. 2003. Soziale Homogenität und generationelle Muster der deutschen Wirtschaftselite seit 1945. In: Die deutsche Wirtschaftselite im 20 Jahrhundert - Kontinuität und Mentalität. Essen: Klartext Verlag für Sozialwissenschaft.

2007. Wer wird Manager? Soziale Schließung durch Bildungsabschlüsse und Herkunft im internationalen Vergleich. In: STICHWEH, R. \& WINDOLF, P. (eds.). Inklusion und Exklusion:
Analysen zur Sozialstruktur und sozialen Ungleichheit. Wiesbaden: VS Verlag für Sozialwissenschaften.

IANNI, O. 1994. Globalização: novo paradigma das Ciências Sociais. Estudos Avançados, São Paulo, v. 8, n. 21, p. 147-163, maio-ago. Disponível em: http://www.scielo.br/pdf/ea/v8n21/09.pdf. Acesso em: 8.ago.2013.

KLUGE, S. \& KELLE, U. 2001. Methodeninnovation in der Lebenslaufforschung. Integration qualitativer und quantitativer Verfahren in der Lebenslauf und Biografieforschung. München: VS Verlag für Sozialwissenschaft.

LÓPEZ-RUIZ, O. J. 2004. $O$ ethos dos executivos das transnacionais e o espírito do capitalismo. Campinas. Tese (Doutorado em Ciências Sociais). Universidade Estadual de Campinas.

LUHMANN, N. 2000. Organisation und Entscheidung. Organização e Decisão. Wiesbaden: Opladen.

MAYER, K. U. 1990. Lebensverläufe und sozialer Wandel. Opladen: Westdeutscher. Disponível em: http://www.gbv.de/dms/hebis-darmstadt/toc/ 13469584.pdf. Acesso em: 12.ago.2013.

MOSS-KANTER, R. 1999. Global Competitiveness Revisited. The Washington Quarterly, Washington (DC), v. 22, n. 1, p. 39-58, Winter.

POHLMANN, M. 2006. Globalisierung und Modernisierung: zentrale Annahmen der Globalisierungstheorien auf dem Prüfstand. In: SCHWINN T. (ed.). 2006. Die Vielfalt und Einheit der Moderne: Kultur und strukturvergleichende Analysen. Wiesbaden: VS Verlag für Sozialwissenschaft.

2007. Management und Führung. Eine managementsoziologische Perspektive. Sozialwissenschaften und Berufspraxis, Münster, v. 30, n. 1, p. 5-20. Disponível em: http://archiv.ub.uniheidelberg.de/volltextserver/8486/1/Management_ und_Fuehrung_Eine_Managementsoziologische_ Perspektive.pdf. Acesso em: 8.ago.2013.

2008. Der diskrete Charme der Bourgeoisie: ein Beitrag zur Soziologie des modernen Wirtschaftsbürgertums. Wiesbaden: VS Verlag für Sozialwissenschaft. 
. 2009a. Globale ökonomische Eliten? Eine

Globalisierungsthese auf dem Prüfungstand der Empirie. Kölner Zeitschrift für Soziologie und Sozialpsychologie, New York, v. 61, n. 4, p. 513534, Dec.

(coord.). 2009b. Economic Elites in Social Change. Pesquisa realizada no período de 20072009 sobre a elite econômica alemã em contexto de mudança social, sob coordenação do Prof. Dr. Markus Pohlmann, da Universidade de Heidelberg, em cooperação com o Prof. Dr. Gert Schmidt, da Universidade Friedrich-Alexander de ErlangenNürnberg.

. (coord.). 2011a. Der neue Geist des Kapitalismus auf der Führungsetage. Pesquisa em andamento.

. 2011b. In der Welt zuhause? Die Soziologie auf den Spuren des globalisierten Managers. Forschungsmagazin Ruperto Carola, Heidelberg, v. 3, p. 36-42. Disponível em: http://archiv.ub.uniheidelberg.de/volltextserver/14989/1/111027-
Ruperto\%20Carola\%20Forschungsmagazinpohlmann.pdf. Acesso em: 8.ago.2013.

POHLMANN, M. \& BÄR, S. 2009. Grenzenlose Karrieren? Hochqualifiziertes Personal und TopFührungskräfte in Ökonomie und Medizin. Österreichische Zeitschrift für Soziologie, New York, v. 3, n. 34, p. 13-40, Dez.

.2011. Familie, soziale Herkunft und Karrieren der Spitzenmanager in Deutschland. In: POHLMANN, M. \& LÄMMLIN, G. (eds.). Neue Werte in den Führungsetagen? Kontinuität und Wandel in der Wirtschaftselite. Karlsruhe: Evangelische Akademie Baden.

SACKMANN, R. 2007. Lebenslaufanalyse und Biografieforschung: eine Einführung. Wiesbaden: VS Verlag für Sozialwissenschaft.

SKLAIR, L. 1991. Sociology of the Global System. London: Harvester Wheatsheaf. . 2001. The Transnational Capitalist Class. Oxford: Blackwell.

\section{OUTRAS FONTES}

BRASIL. ME. 2013. Programa Ciência Sem Fronteiras. Estatísticas e indicadores. Disponível em: http://www.cienciasemfronteiras.gov.br/web/ csf/estatisticas-e-indicadores/. Acesso em: 12.ago.2013.

Estamos na era do executivo infiel. 2013. Exame, São Paulo, "Cultura", 2.maio. Disponível em: http:// exame.abril.com.br/revista-exame/edicoes/1040/ noticias/a-era-do-executivo-infiel. Acesso em: 12.ago.2013.
MPI. 2007. US Immigration, Borders, and Security. Disponível em: http://www.migrationpolicy.org/ research/usimmigration.php. Acesso em: 12.ago.2013.

DESTATIS. 2013. Mikrozensus. Disponível em: https:/ /www.destatis.de/DE/ZahlenFakten/ GesellschaftStaat/Bevoelkerung/Mikrozensus.html. Acesso em: 12.ago.2013. 
ECONOMIC ELITES IN BRAZIL: A STUDY OF THE INTERNATIONALIZATION OF TOP MANAGER'S CAREERS.

\section{Markus Pohlmann and Elizângela Valarini}

The main objective of this paper is to examine the hypothesis regarding the internationalization of Brazilian industrial top management in the context of globalization. This hypothesis is intrinsically linked to theories of globalization, which indicate the emergence of a global economic elite whose particularities are, among other things, a high performance and high social mobility. Through empirical observation of biographies and career paths, as well as the international mobility of top executives in Brazil, we aim to verify the emergence of a new career pattern, i.e., global careers, as an effect of globalization..

KEYWORDS: brasilian economic elite; brasilian executives; top manager; international career; international recruitment. 